\title{
O sujeito inexistente: reflexões sobre o caráter da consciência fonológica a partir do "Relatório final do grupo de trabalho alfabetização infantil - os novos caminhos"
}

\author{
Eduardo Calil \\ Adna de Almeida Lopes \\ Universidade Federal de Alagoas \\ Cristina Felipeto \\ Universidade de Ciências da Saúde de Alagoas
}

\author{
Correspondência: \\ Eduardo Calil \\ Rua Jader Izidio M. de Araújo, 48 - \\ apto. 101 \\ 57030-660 - Maceió - AL \\ e-mail: eduardocalil@hotmail.com
}

\section{Resumo}

Este artigo busca debater alguns trabalhos para os quais o sucesso na aprendizagem da leitura e escrita deve ter como base principal a consciência fonológica. Assim, do "Relatório final do grupo de trabalho alfabetização infantil: os novos caminhos", publicado pela Câmara dos Deputados em 2003, questionaremos pontos específicos, tais como a metodologia utilizada e o conseqüente tratamento de higienização dos dados, a relação fonema/ grafema e a noção "chave" de consciência fonológica como fonte do (in)sucesso da leitura e escrita. Debateremos ainda trabalhos nos quais está subjacente a busca de um "estágio ideal" de ligação entre consciência, memória e aquisição da escrita. Os autores também evocam a importância da consciência fonológica para a aquisição de regras ortográficas e apontam a existência de um sujeito consciente que evolui em estágios de desenvolvimento. A partir de nosso campo de pesquisa, qual seja, o da aquisição de linguagem, e questionando e nos contrapondo à metodologia de seleção de dados estatisticamente relevantes por meio do método experimental, buscaremos mostrar, mediante a análise de erros singulares, que a relação entre sujeito e língua não pode ser pautada por uma análise metalingüística, sob pena de perder-se a singularidade do sujeito. Desse modo, argumentamos que, ao largo das competências e habilidades que o aluno, segundo aqueles estudos, deve desenvolver/adquirir por meio do defendido método fônico, há desde sempre uma língua que, em seu funcionamento simbólico, enreda o sujeito em suas tramas.

\section{Palavras-chave}

Alfabetização - Erro ortográfico - Singularidade - Relação fonemagrafema. 


\title{
The inexistent subject: reflections on the nature of phonological awareness based on the "Final report of the workgroup Child Literacy - the new paths"
}

\author{
Eduardo Calil \\ Adna de Almeida Lopes \\ Universidade Federal de Alagoas \\ Cristina Felipeto \\ Universidade de Ciências da Saúde de Alagoas
}

Contact:

Eduardo Calil

Rua Jader Izidio M. de Araújo, 48

- apto. 101

57030-660 - Maceió - AL

e-mail: eduardocalil@hotmail.com

\section{Abstract}

This article seeks to discuss some works to which the success in learning to read and write must have as its main foundation the phonological awareness. Thus, we shall question specific points of the "Final Report of the workgroup on Child Literacy: the new paths" published by the Brazilian Federal House of Representatives in 2003, such as the methodology employed and the corresponding treatment of cleansing of the data, the phoneme/grapheme relation and the "key" notion of phonological awareness as the source of (un)successful reading and writing. We shall also debate works, to which is subjacent the search for an "ideal stage" of connection between consciousness, memory and acquisition of writing skills. The authors also evoke the importance of the phonological awareness to the acquisition of orthographic rules, and point out the existence of a conscious subject who evolves in stages of development. Starting from our field of study, namely the acquisition of language, and questioning and opposing the methodology of selection of statistically relevant data through the experimental method, we try to show, using the analysis of singular mistakes, that the relation between subject and language cannot be based on a metalinguistic analysis, or we risk losing sight of the subject's singularity. In this way, we argue that beyond the competencies and abilities that the pupil, according to those studies, must develop/acquire through the proposed phonic method, there is always a language which, in its symbolic workings, entwines the subject in its weaving.

\section{Keywords}

Literacy - Orthographic mistake - Singularity - Phoneme-grapheme relation 
L'écriture et la lecture réclament une mise en acte $d u$ refoulement, sans laquelle celui qui voit les signes restera attaché à leur forme et n'arrivera pas, par conséquent, à dégager une valeur littérale subsistant seulement dans leur effacement. (Gérard Pommier)

Não é complicado reconhecer o pensamento que se alimenta de identificações:

é a ladainha das certezas. (Contardo Calligaris)

A Câmara dos Deputados publicou, no ano de 2003, o "Relatório final do grupo de trabalho alfabetização infantil: os novos caminhos" (Brasil, 2003), organizado por uma comissão de especialistas ${ }^{2}$ com a finalidade de "apresentar ao Brasil uma visão atualizada sobre as teorias e práticas de alfabetização como base para uma análise da situação brasileira" (Brasil, 2003, p. 8, grifo nosso). 0 documento convida para o debate todos os segmentos sociais responsáveis pela Educação, entre eles a comunidade acadêmica. Dessa forma, sentimo-nos instigados a atender ao convite ${ }^{3}$, levantando uma discussão relacionada à Aquisição da linguagem, nossa área de atuação em pesquisa - especificamente no que diz respeito ao tratamento dos erros singulares, descartados dos estudos apresentados no REL -, e à relação fonia/grafia nos processos de leitura e, mais especificamente, de escrita.

A problemática tratada pelos especialistas que compuseram o REL apresenta o conceito de "consciência fonológica" como sendo "o mais importante preditor de sucesso em leitura [que] possui a força equivalente à do conceito de gravitação em física" (p. 18) ou, ainda, como sendo "o fato científico mais importante produzido pela ciência cognitiva da leitura, nos últimos 30 anos" (Adams apud Brasil, 2003, p. 37), já que a "consciência fonêmica" e o "domínio do princípio alfabético" são dois conjuntos de competências que estabelecem o valor preditivo para a leitura.

Sustentados por esses conceitos e pelos estudos experimentais filiados à Psicologia
Cognitiva (Adams, 1990; 1993; Bradley; Bryant, 1983; Smith, 1971; 1973, entre tantos outros), cuja metodologia de pesquisa prioriza os critérios de regularidade, freqüência, previsibilidade e o desenvolvimento de habilidades de percepção e memorização, o REL apresenta sua veemente defesa em favor do método fônico como solução para os problemas de alfabetização do Brasil.

A importância dada às habilidades acima descritas mostra não só o papel que se atribui à noção de "consciência" nos estudos sobre leitura, quanto o pretendido caráter explicativo dos processos cognitivos fundados em um quadro teórico denominado pelos autores de "nova" Ciência Cognitiva da Leitura. Segundo esse referencial, essas pesquisas procuram cercar suas hipóteses por meio do "uso de metodologia experimental, primeiro em laboratórios, depois em trabalhos de campo" (Brasil, 2003, p. 17).

0 escopo metalingüístico da noção de "consciência" advogado pelos estudos descritos no REL, assim como pelas investigações que tomam a aquisição do sistema ortográfico como questão, mantêm uma relação de proximidade não só teórica, mas também metodológica. Essa aproximação está explicitada ao se afirmar que

[...] sem consciência fonêmica - isto é, sem saber que cada palavra é constituída de uma seqüência de sons - o aluno terá dificuldade para compreender a ortografia de uma língua alfabética - restando-lhe como opção decorar todas as palavras com base na sua aparência. (p. 99)

As conseqüências dessa afirmação colocam não só a "consciência metalingüística" como noção-chave para o processo de aquisição do sistema de escrita, mas ainda sua ausência impede qualquer acesso do aluno ao seu

1. Para facilitar a referência ao relatório, passaremos a denominá-Io simplesmente por REL.

2. Gostaríamos de ressaltar, sem colocar em suspeita o caráter cientifico do relatório, que todos os integrantes vinculam-se à Psicologia Cognitiva como campo teórico e metodológico de investigação, sendo dois deles, inclusive, autores de métodos fônicos de alfabetização.

3. Agradecemos ao Professor Doutor Claudemir Belintane a oportunidade expressa em seu convite para debatermos o REL. 
funcionamento, na medida em que está relacionada a habilidades cognitivas

[...] tais como: segmentar e manipular a fala em suas diversas unidades (palavras, sílabas, fonemas); separar as palavras de seus referentes (ou seja, estabelecer diferenças entre significados e significantes); perceber semelhanças sonoras entre palavras; julgar a coerência semântica e sintática de enunciados. (Barreira; Maluf, 2003, p. 492)

0 desenho metodológico experimental classifica, seleciona e interpreta aqueles dados estatisticamente relevantes. É o caso do estudo, por exemplo, apresentado por Moreira e Pontecorvo (1996, p. 86) quando "classificam" alguns erros ortográficos da palavra "chapeuzinho" como "inclassificáveis" ou "inconsistentes" uma vez que aparecem nos textos analisados pelas autoras "apenas uma ocorrência da palavra", "apenas duas diferentes grafias [no mesmo texto]". A exclusão desses erros, por terem caráter incidental e imprevisível, faz com que não sejam interpretáveis, constituindo assim uma zona obscura cujo olhar dos autores não ilumina. Com esse impedimento, quebra-se o compromisso ético com o erro e sua dimensão real que impede qualquer análise e classificação totalizante e cartesiana.

Um estudo longitudinal sobre a aquisição de regras ortográficas, a partir do princípio de que "os sistemas de escrita não são fiéis à sua base fonológica”, foi realizado por Rego e Buarque (1997, p. 199) com crianças brasileiras, para testar um estudo com crianças inglesas (Rego; Bryant, 1993), cuja hipótese sugeria que o desenvolvimento da "consciência sintática" facilita o processo de aquisição de regras ortográficas.

Inseridos nas pesquisas que enfocam o "desenvolvimento de competências metalingüisticas" relacionados à aprendizagem da leitura e da escrita, esses autores observam, especificamente, dois campos dessa competência:

a) consciência fonológica - relacionada apenas à compreensão do princípio alfabético, envolvendo a decodificação da leitura; e b) consciência sintática - relacionada ao uso do contexto na leitura de palavras com dificuldades ortográficas, que envolve compreensão em leitura, além da decodificação,

[...] chegando à conclusão de que: "a consciência sintática é um facilitador específico da aquisição de regras ortográficas que envolvem análises morfo-sintáticas, enquanto que a consciência fonológica contribui principalmente para a aquisição de regras de contexto grafo-fônico". (Rego; Buarque, 1997 p. 199)

Os autores se propuseram a investigar as contribuições desses estágios de consciência, diferenciando a natureza das regras ortográficas:

- As que se apóiam na análise de contextos fonológicos, mediante opções gráficas como, por exemplo, o som do /g/ em "gato", "guerra" e "guidon"; e

- As que não são definidas em função do som, mas da classe gramatical como, por exemplo, o ditongo /iw/ em "partiu”, "navio" e "barril".

Desse modo, estão definidas aí, segundo os autores, as regras de contexto grafo-fônico, que "acionam" apenas a "consciência fonológica", e as regras que envolvem análise gramatical, que necessitam da "conexão" da "consciência sintática":

[...] a consciência sintática não deve distinguir aquelas que evoluiram mais das que evoluíram menos quanto à aquisição de regras ortográficas que envolvam apenas análises grafo-fônicas. A consciência fonológica deve ser o aspecto da consciência metalingüística especificamente conectado com a aquisição deste último tipo de regra ortográfica. (Rego; Buarque, 1999, p. 204)

A partir dos comentários dos autores sobre os seus resultados, podemos fazer aqui uma reflexão sobre três pontos:

1) A análise tem como pressuposto a existência de um sujeito "consciente" e em "desen- 
volvimento" para distinguir os erros das "palavras" que possuem uma relação com a oralidade ou com as outras "unidades" contextuais dessa palavra:

[...] a aquisição de regras ortográficas que envolvem análise gramatical é facilitada pelo desenvolvimento da consciência sintática enquanto que a consciência fonológica contribui especificamente para a aquisição de regras ortográficas que envolvem apenas uma análise do contexto grafo-fônico. (Rego; Buarque, 1999, p. 216)

2) 0 estudo mostra que a consciência fonológica não dá conta da aquisição da ortografia, mas apenas de um aspecto dela: regras que dependem da análise do contexto grafofônico e mesmo a consciência sintática não dão conta da aquisição de regras que envolvam "análise gramatical":

[...] a consciência fonológica não constitui um fator determinante na aquisição de regras ortográficas que, em última análise, dependem da utilização de critérios gramaticais, mas que está relacionada à aquisição de regras ortográficas de outra natureza, isto é, aquelas que dependem de uma análise mais minuciosa do contexto grafo-fônico da palavra para verificar qual a grafia que se aplica. Por outro lado, constatou-se também, que diferenças de desempenho em tarefas de consciência sintática não são relevantes para a aquisição de regras que não envolvam diretamente análise gramatical .(Rego; Buarque, 1999, p. 217)

3) 0 estudo mostra que o dado longitudinal não dá conta para confirmar uma relação entre consciência sintática e aquisição de regras:

[...] o dado longitudinal ainda não é suficiente para estabelecer relações de causalidade entre consciência sintática e aquisição de regras ortográficas. São necessários, portanto, estudos de intervenção em sala de aula que permitam verificar se, de fato, existe uma relação causal e específica entre o desenvolvimento desses aspectos da consciência metalingüistica e a aquisição de regras ortográficas de natureza distintas. (Rego; Buarque, 1999, p. 217)

Os três aspectos apontados têm em comum: um sujeito consciente que evolui em estágios de desenvolvimento; um sujeito que usa e analisa a língua; e a busca de um estágio ideal de ligação entre consciência, memória e aquisição da escrita.

A partir daí, direcionaremos os comentários neste artigo interrogando os dados oriundos de pesquisas generalizantes que têm desprezado as considerações sobre o sujeito e sua singularidade, bem como a metodologia utilizada, ao apresentarmos alguns erros que possam ajudar a colocar em suspensão uma relação entre sujeito e língua, pautada pela análise metalingüística.

\section{O lugar repetível da singularidade}

Se relacionarmos a inscrição do singular numa repetibilidade, poderemos acatar o conceito de ciência de Milner (1989, p. 21), especificamente a ciência lingüística, como possível de ser matematizada. No entanto, a matematização de que fala o autor não trata de quantificação (medida), de repetição do conteúdo, mas de uma repetição do fenômeno ou o que o autor chama de "reprodutibilidade das demonstrações".

Refletir sobre esse movimento de repetição que tem como efeito uma forma de erro, chiste, ato falho ou mesmo uma produção escrita "estranha", significa dizer, de acordo com Leite (2000, p. 41), mais sobre os "efeitos de sua presença no campo de estudos da linguagem", do que procurar defini-la fora de um evento de língua.

Estamos considerando que, na emergência do singular, há uma repetição do fenômeno lingüistico. É diferente, portanto, da repetição considerada nos estudos experimentais de diferentes campos, tanto da Psicologia como da lingüística, apoiada apenas na busca 
de regularidade de um certo tipo de erro.

Comentando a dificuldade das teorias da linguagem em considerarem o singular pela sua resistência a tentativas de teorização, uma vez que sempre "escapa e sobra", Rajagopalan reforça o pensamento de Milner quando enfatiza que, apesar dessa dificuldade, as teorias admitem reconhecer que:

[...] a singularidade é algo que desafia o próprio empreendimento da construção de teorias sobre a linguagem [...]. Em outras palavras, pensar a singularidade equivale a entrar na zona limítrofe do pensamento acerca da linguagem. Persistir em tal interrogação significa preparar o caminho para o próprio desmoronamento do empreendimento da teorização, do esforço de imobilizar a linguagem dentro da camisa-de-força de uma teoria totalizante. $(2000$, p. 83$)$

Vale a pena destacar, para a análise dos erros ortográficos singulares que faremos neste trabalho, outra diferenciação, desta vez estabelecida por Lier-De-Vitto entre o singular e o individual:

Singular e individual não são termos sinônimos: o primeiro - o singular - é irredutível, como disse, insiste como diferença; já o segundo - o individual - faz série numa classe ou conjunto de semelhantes. Por essa razão, ele é tomado como exemplar. Resumidamente, a operação (regularizadora) da analogia, da determinação de similaridades entre acontecimentos, não se aplica ao termo singular, sempre abordável pelo lado da diferença, do que não tem par, do que não faz série. (2004, p. 48)

Essa segunda diferenciação coloca o singular como lugar marcado pela diferença, direção contraria às muitas tendências metodológicas que tomam tanto o individual como o repetível como fator determinante do desenvolvimento e da aprendizagem. Apesar de essa dimensão universalizante ser legítima, ela não poderia supor-se única, sem correr o risco de falsear a relação entre sujeito e língua.

\section{A singularidade expulsa do recorte metodológico}

Olhar para o dado singular não tem sido um procedimento presente e constante nas pesquisas que envolvem aquisição e aprendizagem de língua escrita, detendo-se de maneira geral na coleta de dados quantitativos e na análise desses dados e visando a uma categorização e adequação à determinada teoria.

Acreditamos, por isso, que as reflexões sobre algumas questões metodológicas da área de aquisição da linguagem que faremos a seguir podem esclarecer algumas diferenças entre essas questões e os procedimentos metodológicos comumente adotados naquelas pesquisas.

A nossa filiação à área de aquisição da linguagem está marcada pelo compromisso com o dado enigmático da fala da criança, (re)velador das relações do sujeito com a língua, conforme pressuposto no trabalho de Lemos (2002).

Convém explicitar, no entanto, que as pesquisas na área de aquisição de linguagem nem sempre tiveram esse direcionamento. 0 "privilégio do regular" parece estar diretamente relacionado à expectativa de conhecimento projetada, pelo pesquisador, sobre o "sujeitoaprendiz". Desse modo, o erro regular seria, pois, um erro produtivo, na medida em que mostra o conhecimento (a apreensão) de uma regra por meio da ultrageneralização, ou seja, a criança estenderia esse conhecimento para outros domínios lingüísticos.

No livro A língua que me falta: uma análise dos estudos em aquisição de linguagem, Lemos (2002) mostra o percurso dos estudos na área, desde a filiação à Psicolingüística até o compromisso do pesquisador com a fala da criança como dado empírico para a constituição desse campo de conhecimento. Ter o dado como empírico implica uma concepção diferente daquela em que esse termo designa: "uma espécie de saber que se adquire através da prática, através da repetição e da memória" (Abbagnano, 2000, p. 325) em oposição à ra- 
cional. Implica, no entanto, mais uma "atitude empírica" que "consiste em ressaltar a importância dos fatos, dos dados, das condições que tornam possível a verificação de uma verdade" (p. 327). Abbagnano (2000, p. 406) apresenta diferentes acepções de empirismo, empírico, experiência. Ele afirma, por exemplo, que nem todos os significados do adjetivo empírico estão relacionados ao substantivo correspondente, ou seja, experiência que, por sua vez, possui dois significados fundamentais: um, relacionado à participação pessoal em situações repetíveis; e outro, à possibilidade de repetir certas situações como meio de verificar as soluções que elas permitem. Fica claro, no entanto, que o "elemento comum" aos dois significados "é a possibilidade de repetir as situações, e isso deve ser considerado fundamental na significação geral do termo”, o que demonstra, segundo o autor, que o termo somente pode ser relacionado ao "único" para indicar "pouca freqüência" e, também, que "pode indicar situações de qualquer natureza em que se possa contar com suficiente repetibilidade”. Assim, podemos concluir que o critério da repetibilidade pode modificar o ponto de vista numa determinada pesquisa, quando se considera ou apenas o objeto (conteúdo lingüístico) ou o movimento da língua ao qual o sujeito está submetido.

A empiria do "erro singular", por meio de sua dimensão imprevisível, irregular, assistemática, enigmática, presente na fala da criança e na escrita do aluno, é o ponto central de estudos em aquisição de linguagem que assumem o compromisso ético com aquilo que pode ser revelador dos pontos de assujeitamento do sujeito à língua.

Indo mais além na discussão sobre a metodologia dos estudos em aquisição da linguagem, Lemos avança quando apresenta a diferença que caracteriza hoje esses estudos em relação à Psicolingüística: a condição de submetimento da pesquisa à fala/escrita da criança que passa a ter a função de enigma ligado ao funcionamento da língua.

0 diferencial levantado pela autora sobre o compromisso do investigador com a fala/escrita da criança como enigma foi fundamental para o fortalecimento de estudos que envolvem a questão da singularidade. Alguns pontos, no entanto, já estavam incorporados às discussões sobre o tratamento dos dados nas pesquisas em aquisição da linguagem que sempre foi marcada, historicamente, por diferentes linhas de pesquisa.

Perroni (1996), no artigo "O que é o dado em aquisição da linguagem?”, comenta que a própria criação da área partiu de dois campos teóricos, a Psicologia e a Lingüística, e que essa interdisciplinaridade permanece, ainda hoje, quando reúne estudos muito diferentes entre si, sem um consenso tanto quanto ao objeto de estudo como aos procedimentos metodológicos das pesquisas. Diante disso, a autora levanta questionamentos, tais como: Qual a posição do investigador que elege a aquisição da linguagem como objeto de seu estudo? Qual metodologia gerará o fato mais objetivo? Qual dará conta da complexidade do objeto?

As reflexões desencadeadas por essas questões mostram-se pertinentes quando confrontadas com o REL. Uma dessas reflexões pode ser estendida à noção de "dado". A autora afirma que o que se tem chamado de "fato" ou "dado", em pesquisas de aquisição de linguagem, toma tratamento diferente dependendo da teoria e do procedimento adotados pelo pesquisador e inicia a discussão apresentando-se contrária a dois tipos de procedimento - aquele centrado no chamado "dado bruto" e aquele centrado numa teoria que exige até mesmo um ajuste dos dados:

Em qualquer reflexão sobre o que é dado, impõe-se questionar se todo e qualquer "fato bruto" (assumindo-se sua existência) serve como matéria para a ciência, ou se afinal são considerados apenas aqueles que cuidadosamente foram previamente selecionados por sua relevância dentro de uma teoria, ou que foram até mesmo remodelados para garanti-la. (Perroni, 1996, p. 17)

Disto se extrai um ponto particular que diz respeito ao REL. Nos estudos experimentais, os 
"dados brutos" seriam tomados como anteriores às teorias, cujo papel seria explicá-los. Eram, assim, considerados independentes a qualquer construção teórica, fazendo uso de grande quantidade de dados para comprovar ou refutar as teorias.

Tais estudos agiam de forma a isolar todas as 'interferências', para se chegar à competência. 0 enfoque na gramática deu origem aos estudos com grande número de sujeitos, ambiente controlado e uso de categorias definidas a priori. (Perroni, 1996, p.18)

Contra esse procedimento metodológico, Carvalho, na mesma linha de alguns outros pesquisadores em aquisição de linguagem, comenta sobre a "higienização do resíduo", isto é, a exclusão ou a transformação dos erros singulares a fim de recompor uma totalidade. Segundo a autora, "esse tipo de erro (regularizador) indica uma certa unidade, uma certa organização, ou melhor, revela um movimento organizador ou, poderiamos mesmo dizer, uma 'intenção organizadora' do investigador projetada sobre a criança” (1995, p. 58).

A higienização a que se refere a autora é ainda mais evidente quando o método eleito é o experimental. Historicamente, no início da década de 1970, a maioria dos pesquisadores em Aquisição de linguagem era constituída por psicólogos e o campo tornou-se proeminentemente experimental ${ }^{4}$, ou seja, agia-se de forma a afastar todas as variáveis. É exatamente desse lugar que fala o REL:

A maioria das pesquisas se baseia no teste de hipóteses envolvendo o uso de grupos experimentais e de controle, que são escolhidos de forma a isolar de outras influências a variável que se quer estudar. (Brasil, 2003, p. 17)

De acordo com Perroni, as supostas vantagens de tal método seriam

[...] a possibilidade de obtenção de informações que, apenas pela observação, não seriam necessariamente obtidas [e] a replicabilidade, ou seja, a possibilidade de os testes serem reapli- cados por outros pesquisadores com sujeitos diferentes. (1996, p. 19)

Além disso, há a possibilidade de a pesquisa abarcar uma quantidade grande de sujeitos, de modo que, estando todos inclusos em tabelas, gráficos e porcentagens, chega-se à generalidade. 0 dado não seria individual, mas grupal, dando uma "ilusão de objetividade":

Baseada numa visão estática da língua, é a metodologia que mais facilmente cai na ilusão de objetividade, vista como sinônimo de descrição do fenômeno lingüístico, depurado de toda e qualquer 'excrescência' que, teimosa e indesejavelmente, insiste em caracterizar suas manifestações. (Perroni, 1996, p. 21)

Poderíamos dizer que a homogeneização dos sujeitos, isto é, o apagamento de sua singularidade, interroga sobre a validade dos resultados obtidos. No intuito de varrer as variáveis, o direcionamento das questões é uma forma de obter um comportamento pretendido, o qual poderia não ocorrer se o método em questão fosse o observacional ou naturalístico. Um dos argumentos a favor do experimentalismo levado a cabo por pesquisadores que se utilizam desse método é que, caso haja falha em determinado teste, é possível estabelecer relações causais, já que a noção de porcentagem serviria como medida de normalidade geral. Entretanto, em busca da causa, anula-se a particularidade de cada sujeito, pois o "dado colhido assim não é individual, é antes do grupo, como abstração" (Perroni, 1996, p. 20).

0 apagamento do dado entendido como singular ${ }^{5}$ pela metodologia experimental é incapaz de produzir um corpo de conhecimentos suficiente para permitir a proposição de questões causais, o que exigiria esclarecer fatores particu-

4. A esse respeito, ver Perroni (1996).

5. A esse ponto, podemos somar como um fator de grande importância a situação atual da alfabetização brasileira. Sua história recente mais de fracassos que de sucessos é um fenômeno de tal amplitude e complexidade que jamais poderá ser resolvida por meio do método "y" ou "z". 
lares e locais. 0 objetivo deveria ser a compreensão do fenômeno considerado em seu caráter ético, o que se torna inviável quando se apaga sua singularidade.

\section{A complexidade do singular: confronto com o resíduo}

Consideramos que, se o funcionamento da língua - definido por Saussure na formulação da teoria do valor - tem como primitivo relações e é estranho a uma ordem perceptual, não há como defini-lo em termos de conhecimento comum a todos os indivíduos. Gadet, comentando Saussure, diz ainda que as unidades da língua seriam produtos de um duplo “mecanismo inobservável" (1987, p. 63), o que aponta para a impossibilidade de o sujeito exercer qualquer tipo de controle sobre esse mecanismo a não ser dentro de uma ordem imaginária em que essas unidades ganham consistência e adquirem valor de verdade.

Esse duplo mecanismo pode ser resumido da seguinte forma. 0 mecanismo metonímico revela a conexão "significante a significante" na cadeia sintagmática. Trata-se do encadeamento de entidades sucessivas, relações estas que se dão in praesentia e é onde o homem encontra o poder de esquivar-se dos obstáculos da censura social, onde o desejo aí investe, encontra seu ponto de expansão. Puro deslize, deriva, a metonímia não é uma figura que "salva" o sentido. Pelo contrário, teima em não se significar. "Meio mais adequado do inconsciente para despistar a censura" (Lacan, 1996, p. 515), a metonimia "inverte os valores, transveste o sentido, torna obscuro, no nível manifesto, o que era significante no nível latente" (Chemama, 1995, p. 224).

0 mecanismo metafórico, por sua vez, implica na substituição de um elemento por outro, substituições que são operadas por similaridade fonética, semântica ou sintática. Uma multiplicidade de cadeias concorrendo para habitar o mesmo espaço. A cadeia manifesta atua como "representante" das cadeias que se encontram em nível latente, como que as encerrando, as condensando.

A relação articulada por meio desse duplo mecanismo vai de encontro à noção "chave" dos estudos da Psicologia Cognitiva, uma vez que a "consciência fonológica" supõe um sujeito que abstrai e infere propriedades da língua, além da dissecação da língua em seus diferentes níveis, a começar pelo fonológico. Uma dessas análises realizadas pelo sujeito diante da língua refere-se à relação fonia/grafia.

Encontramos aqui um ponto de aproximação bastante relevante e fortemente presente nos estudos sobre a aquisição do sistema ortográfico, uma vez que tais investigações encontram suas justificativas nessa relação para explicar as ocorrências de erros e seus aspectos cognitivos e perceptuais como determinantes para a sua produção. Além disso, os tipos de erros descritos nesses trabalhos (Pothier, 1996; Nunes et al., 2000; Morais, 1998; 2002; Rego; Buarque, 2002; Tafla, 1994) são aqueles submetidos à previsibilidade do sistema e à categorização.

Colocando em suspeição as hipóteses de "autonomia”, "consciência” e "operação" do sujeito sobre a língua, pretendemos então tecer algumas considerações sobre o processo de entrada do sujeito no mundo da escrita, procurando discutir o estatuto da consciência fonológica, que envolve a relação fonia/grafia, mediante erros ortográficos que apresentam um caráter singular, isto é, do ponto de vista dos estudos cognitivistas são erros considerados estatisticamente irrelevantes, não sistemáticos e não categorizáveis. Da perspectiva assumida, esses erros teriam uma importância capital para se refletir sobre a relação entre sujeito e língua, tendo como fundação teórica e incontornável a ordem simbólica da linguagem.

Iremos expor e analisar alguns erros ortográficos singulares - higienizados pelo controle de "variáveis" no método experimental - extraídos de manuscritos escolares escritos em situação de sala de aula, pertencentes ao acervo "Práticas de textualização na escola". Tomaremos dois manuscritos escritos por alu- 
nos já alfabetizados, o que significa supor alguma "capacidade" em decodificar e compreender o "princípio alfabético" de forma consistente e consciente.

Pretendemos com isso trazer alguns elementos que possam ajudar a avançar na interpretação daqueles erros que seriam desconsiderados no modelo teórico proposto pela Ciência Cognitiva.

\section{Suspendendo algumas certezas}

Os primeiros erros singulares que iremos analisar estão presentes na escrita de um aluno da $4^{\text {a }}$ série do ensino fundamental e é freqüentemente classificado como "troca de letras". Entretanto, mostraremos como a singularidade aponta para um funcionamento que difere daquele suposto pelas habilidades cognitivas e perceptuais. Um funcionamento em que as "unidades lingüísticas" não se definem por si mesmas, mas, como afirma Milner (2002, p. 35) ${ }^{7}$ sobre a noção saussureana de valor lingüístico: "o signo só tem propriedades pelas relações de diferenças que mantém seus significantes com todos os outros significantes da língua”.

No texto que analisaremos a seguir, o aluno escreve "raDo" por raBo, "aBora" por adora e "eDinca" por "e BRinca", trocando as formas significantes $B / D, D / B$ e $B R / D$, levando-nos assim a uma interpretação diferente daquela em que as trocas de B/P e P/B são justificadas apenas pela distinção nos traços surdo/sonoro. Optamos por usar o termo "forma significante" por duas razões. A primeira delas pretende evitar o entendimento de que se trata aqui de "letra", "fonema", "sílaba" ou "palavra" e suas relações com as noções de "vogal" e "consoante", pois, como veremos, a presença dessa forma em algumas posições sintáticas abala a unidade que esses termos carregam. A segunda razão refere-se ao caráter diferencial constitutivo do próprio estatuto significante, na medida em que a forma pode ser destituída de conteúdo ou de sentido. Assumiremos ainda que a forma significante pode ter uma manifestação gráfica e uma manifestação fônica. Evidentemen- te, essa questão não é tão simples se se considerar as homonimias entre "letra" (no sentido "lingüístico"), "letra" (conforme trata Lacan) e mesmo entre "forma significante" (como trata a lingüística) e "significante" lacaniano. Sem querer desviar a atenção do leitor para essa espinhosa querela, assumiremos os riscos dessa delimitação.

0 texto do aluno foi produzido num teste de avaliação de habilidades de leitura e escrita e está apresentado abaixo. Após o manuscrito, apresentaremos sua transcrição ortográfica.

\section{Manuscrito 1}

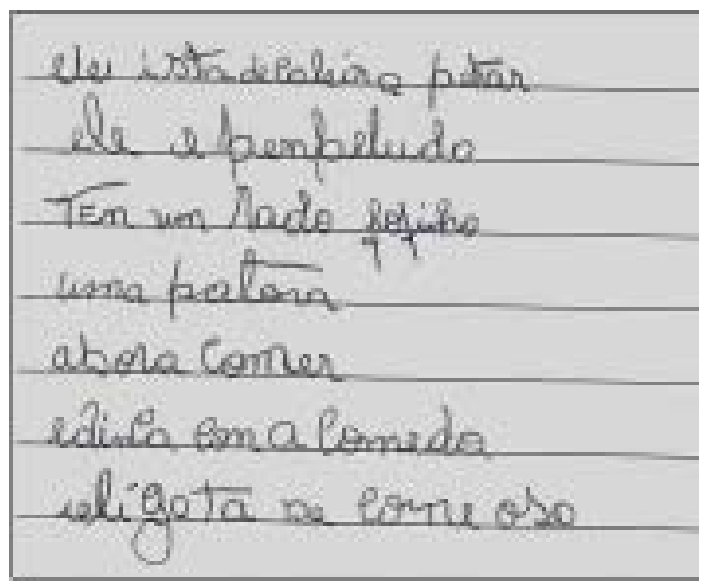

Transcrição do Manuscrito 1
1. ELE ISTA DE COLEIRA PETAR
2. ELE E PENBELUDO
3. TEM UM RADO FOFINHO
4. UMA PATONA
5. ABORA COMER
6. EDINCA COM A COMEDA
7. IELI GOTA SE COME OSO

6. Esses manuscritos compõem o banco de dados do Projeto Integrado de Pesquisa Manuscritos escolares e processos de escritura: histórias, fábulas e poemas no Ensino Fundamental - vinculado ao Grupo de Pesquisa: Ensino, Texto e Criação, Coordenado pelo Prof. Dr. Eduardo Calil de Oliveira, do Programa de Pós-Graduação em Letras e Lingüística e Centro de Educação/UFAL, Maceió - AL.

7. As referências neste trabalho às obras publicadas na língua francesa foram traduzidas por nós: Milner $(1987,2002)$ e Pothier (1996). 
Pelo que pode ser observado, há nesse texto diferentes tipos de erros ortográficos que envolvem tanto a omissão como a troca de letras (Morais, 1998; Nunes et al., 2000). Os primeiros podem ser exemplificados pelas formas: "goÆta" (gosta), “comeÆ” (comer); “osÆo” (osso); e os outros, pelas formas "Ista” (está), "PeNBeludo" (bem peludo), "raDo" (rabo), "aBora” (adora), "comEda” (comida), "ieli” (e ele). Para casos como "petar" (preta), Tafla (1994) classifica como erro por transposição.

As trocas de letras, nesses estudos, são tidas como erros de grafia ligados à língua oral, que ocorrem principalmente pela identificação com pares mínimos, fonemas com apenas um traço distintivo como, por exemplo, o traço surdo/sonoro em /p/ e /b/, /f/ e /v/, /t/ e /d/. Pothier (1996, p. 77) define-os como "erros ligados à oposição de sonoridade”, concluindo pelo número de ocorrências que "os alunos possuem uma forte tendência de ensurdecer os fonemas".

Para questionar as relações fonia/grafia nos processos de escrita, buscaremos explicações para as trocas inusitadas de B/D em "raDo" (linha 3), de D/B em "aBora” (linha5) e de BR/ D em "eDlnca” (linha 6), que nos levam assim a uma interpretação diferente daquela em que as trocas de $\mathrm{B} / \mathrm{P}$ e $\mathrm{P} / \mathrm{B}$ são justificadas apenas pela distinção nos traços surdo/sonoro.

\section{A troca de B/D em raDo (RABO) e a de D/B em aBORA (ADORA)}

Os casos de trocas das formas B/D e D/ B, observados na escrita de "raDo" e "aBora", apresentam alguma estranheza em relação ao que se tem categorizado nos estudos sobre 0 erro ortográfico. A diferença de traços na troca do /b/ pelo /d/ não se dá nem pela fonação (as duas são sonoras) nem pelo modo de articulação (as duas são oclusivas), mas pelo lugar de articulação (a primeira é bilabial e a outra, dental).

Essas trocas poderiam ser justificadas por uma relação fonia/grafia? Poderíamos supor que no dialeto do aluno ele pronunciaria ['radu] e [a’bora], em vez de "rabo" e "adora”? Não haveria entre B (em aBora) e D (em raDo) um ponto de identificação imaginária que se daria a partir da semelhança fonética entre / $b /$ e /d/, favorecendo uma espécie de intercâmbio, de alternância na relação gráfica?

Pelas nossas observações sobre a singularidade nas trocas de $\mathrm{B} / \mathrm{D}$, esse aluno encontra-se enredado, por uma ordem imaginária, com a "face material" da escrita (Mota, 1995), ou seja, com o traçado das letras. Ele escreve alternando os lugares possíveis tanto para B como para $\mathrm{D}$, uma vez que o eixo imaginário possibilita evidenciar “o caráter objetável da letra" (Mota, 1995, p. 134). 0 erro ortográfico estaria, sim, produzindo novas relações e deslocamentos num movimento que enreda as formas significantes e o sujeito inscrito no funcionamento da língua, como diz Bosco, em consonância com Mota (1995):

Trata-se, pois, de significação e ressignificação simbólicas que não se dão ao acaso, mas num movimento que obedece aos processos metafóricos e metonímicos, estes últimos possibilitando o estabelecimento de relações imaginárias de semelhança e dessemelhança que têm efeito de diferença. (Bosco, 2002, p. 143)

A esse fenômeno, essa autora chama de "movimento de significantes na rede de trajetos associativos” (Bosco, 2002, p. 89), cujo caráter é imprevisível, mas não aleatório, produzindo semelhanças e diferenças. Só que, com Lemos, ela afirma que "o efeito de semelhança implica a emergência da diferença” (p. 156).

Podemos ter, assim, o erro como um fenômeno que, por um lado, quebra alguma coisa tida como regular na língua, quando se confronta com os outros fatos (externos) que a gramática e a lingüística têm categorizado como 'correto'; e por outro, revela que mesmo no diferente e estranho fenômeno descartado, ou seja, no irregular, há uma ordem interna (a ordem da língua) que o sustenta e o legitima. Subjacentes a essas formas, há pois um movimento de linguagem que 
tem como base os processos metafóricos e metonímicos como mecanismos de funcionamento da língua (Lemos, 1992; 1997; 1999). Explicitaremos isso um pouco mais.

\section{A troca de BR/D em eDinca (e BRinca)}

Se as relações constatadas acima sobre $o$ erro envolvendo as trocas do /b/ pelo / $/$ / forem certas, o que dizer da escrita de "eDinca" (e BRinca), forma significante na qual o /d/ toma o lugar do encontro consonantal ${ }^{8}$ formado por uma oclusiva bilabial e outra vibrante, ambas sonoras? Será que estaria ligada à transcrição da fala do aluno? Seria o registro de uma 'falha' no valor sonoro convencional da palavra?

De acordo com os pressupostos definidos anteriormente, poderíamos dizer que a troca do /d/ por [bt] está "engendrada" (Mota, 1995; Bosco, 2002) no funcionamento da língua, pelo jogo de significantes, tanto na posição que ocupa como na articulação com os outros e na relação com o ausente.

A posição ocupada por $/ d /$, registrado pelo aluno em "eDinca”, pode ser considerada estranha, mas a sua realização é uma possibilidade de língua, se considerarmos como legítima a existência da sílaba CVC, como em DIN ("DINda", "DINgo", "DINdon") em português. Forma semelhante é registrada pelo aluno no início do texto: "PENbeludo" ("bem peludo") 9

Poderíamos supor, também, se a ausência do /r/ em "edøinca" (e brinca) não estaria numa relação de semelhança e diferença com a ausência (também do /r/, na mesma posição de encontro consonantal, na forma significante "petaR" [preta]), registrada no final da primeira linha do texto do aluno. Apesar de outras formas já estarem bem estabilizadas como, por exemplo, o ditongo decrescente El em "colElra" (linha 1) e o dígrafo $\mathrm{NH}$ em "fofiNHo" (linha 3), o mesmo não acontece com o registro de formas com encontro consonantal ou com relações aparentemente mais simples como "comida", escrita no manuscrito do aluno como "comEda".
Além desses "possíveis de língua” (Milner, 1989) parece haver também um outro ponto fundamental interferindo na constituição desse erro singular. Se entendermos que há entre as formas B e D um elo imaginário de ordem gráfica e posicional que produziu as "trocas" em "raDo" e "aBora”, parece ser possível que o erro "eDlnca" seja ainda um efeito dessa relação à medida que $\mathrm{D}$ assumiria um valor homofônico à forma B. Contando com a ausência de /r/, comentada anteriormente, e supondo essa relação homofônica entre B e D atravessando a produção da escrita de "eDlnca", teríamos de fato uma tentativa de o aluno escrever "eBlnca", erro mais "aceitável" para os estudos sobre as categorizações dos erros ortográficos. Fica evidente, então, que "eDlnca" é, em verdade, "eBlnca", mas a homofonia constituída entre as formas D e B por esse sujeito dá uma dimensão outra para a produção de "eDlnca" e a singulariza.

Há, na escrita de "eDlnca", uma troca inusitada de oclusivas com diferentes pontos de articulação /b/ e /d/, além da omissão da vibrante /r/, já previstas nas categorizações. Ou seja, na própria estranheza do erro, perpassa possibilidades da língua, inscritas numa relação de semelhança com as regularidades da língua nas quais se admite sílabas iniciadas por CVC, como em "CANto", "GENte" e "TINta". Como pretendemos mostrar, há um sistema subjacente que mostra uma ordem na ocorrência do erro, mesmo quando ele se apresenta inusitado.

Estendendo a discussão sobre a busca do "ideal alfabético" nos estudos sobre a ortografia, levantada por Gonçalves (1992), gostaríamos de mostrar, com Barthes e Marty (1987, p. 39), que há, em verdade, uma relação estrutural, mas não dependente entre oral/escrito, o que eles chamam de "produção da língua”: "a escrita já não é uma simples transcrição, mas produção da língua; a escrita deve ser considerada, antes de mais nada,

8. Segundo Crystal (1997, p. 93), "nem todas as combinações possíveis de consoantes ocorrem em uma LíNGUA. [...] Em português, os encontros são formados geralmente por uma consoante OCLUSIVA seguida de $r$ ou / [...], mas existem outras combinações, como em pneu."

9. Cf. análise dessa ocorrência em Lopes (2005). 
como modo de produção da língua, cujos meios conheceram variações notáveis”. E, ainda:

Não se pode considerar a escrita uma contrapartida exata da linguagem falada. Esse estado ideal de correspondência ponto por ponto, em que qualquer elemento da língua seria notado por um signo único, em que um único signo exprimiria, por sua vez, um único elemento da língua, nunca se atingiu numa escrita; até o alfabeto mais elaborado ultrapassa os limites do discurso, tal como o discurso ultrapassa a escrita. (Gonçalves, 1992, p. 44)

Diferentemente dos estudos que buscam uma explicação para o erro ortográfico apenas pela relação fonia/grafia, buscamos interpretá-lo como efeito do movimento entre as formas significantes e o sujeito inscrito no funcionamento da língua.

\section{Quando L pode ser L. /u/, /o/, /um/, 1, AE ...}

Outro dado ${ }^{10}$ que apresentaremos em seguida buscará aprofundar nossos argumentos diante da questão ética imposta aos pesquisadores em Aquisição de Linguagem no tocante aos "erros" de escrita de alunos.

A presença da forma $\mathrm{L}$ e suas posições ao longo de um enunciado escrito podem ter na relação fonema-grafema uma imagem falseada e produzir erros ortográficos inusitados, rompendo com a previsibilidade de suas relações e colocando em xeque seu estatuto fônico, lexical, morfológico, sintático e semântico. Veremos algumas dessas posições encontradas em um manuscrito escrito por dois alu$\operatorname{nos}^{11}$, no dia 29/08/1997, quando freqüentava a $2^{\text {a }}$ série do ensino fundamental.

Manuscrito 2

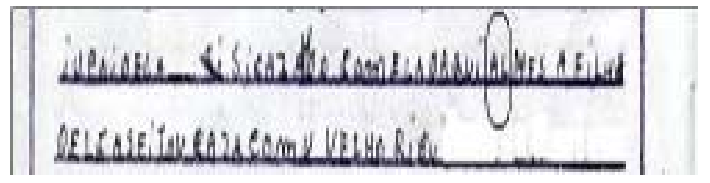

Transcrição do Manuscrito 2

1 U PAI DELA SI CAZA(N)DO COM ELA DAQUI A 1 MÊS A FILHA

DELE ASEITOU CAZA COM U VELHO RICU (linhas 12 e 13)

Manuscrito 3

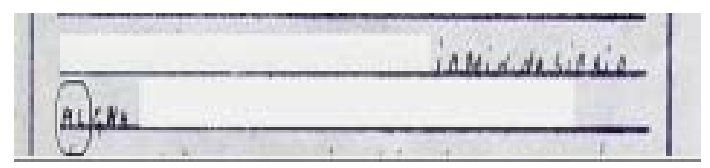

Transcrição do Manuscrito 3

1 A MININA SI CAIO

AL CHA(0) - (linhas 16 e 17)

Manuscrito 4

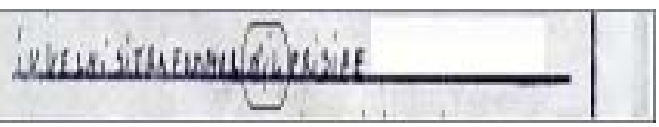

Transcrição do Manuscrito 4

1 U VELHI SI TRA(NS)FORMOL NI L PRISIPE

- (linha 19)

Manuscrito 5

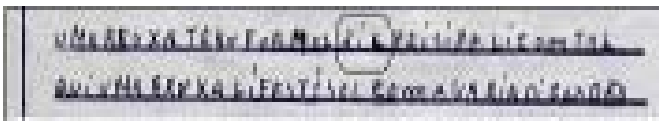

Transcrição do Manuscrito 5

UMA BRUXA TRAN(S)FORMOL NI L PRISIPE LI COMTOL

QUI UMA BRUXA LI FESTISOL COM A VARIA

DI CORDAO - (linhas 20 e 21)

10. Uma análise mais detalhada desse dado pode ser encontrada no artigo "D'efeitos d'a(língua): o fenômeno lingüístico "homortográfico" (Calil, no prelo).

11. Apesar de dois alunos estarem combinando a história inventada que deveriam escrever, até a linha 11 um dos alunos (Anderson, 11 anos) é quem está escrevendo. Após essa linha, quem passa a escrever é o aluno Jaques, com 9 anos e 8 meses. Iremos analisar os erros produzidos por esse aluno. 
Manuscrito 6

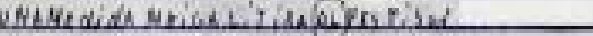

Transcrição do Manuscrito 6 UMA MENINA MEIGA LI TIRA O L FESTISON (linha 22)

Nesses cinco fragmentos, encontramos a forma $\mathrm{L}$ em distintas posições que vão desde as mais estabilizadas como nas palavras “ela”, "filha”, "dele” e "velho", presentes em vários desses fragmentos, passando pelos erros clássicos descritos pela literatura em que essa forma apresenta-se nos finais de verbos no pretérito perfeito da $3^{\text {a }}$ pessoa do singular ("transformou/L", fragmento 4 e 5 ; "contou/L" e "enfeitiçou/L”, fragmento 5), até encontrá-la em posições pouco suspeitas como no lugar de numeral ("daqui a um/L mês", fragmento 2) e de artigo masculino indefinido ("em um/L príncipe”, fragmento 5), restando ainda sua manifestação incerta no fragmento 6: "Ihe tirou o/L feitiço".

Por que o aluno não opta por uma forma, ainda que equivocada, porém mais estabilizada na língua? Por que é a forma $\mathrm{L}$ que se manifesta nessas posições e não a forma $U$ ou ainda UM que os alunos parecem conhecer tão bem, como atesta suas presenças em "u pai dela" (fragmento 2), "u velhi" (fragmento 4), "uma bruxa” (fragmento 5), "uma menina" (fragmento 6)? Por que ele "quebra" a estrutura silábica ao escrever um "som" com apenas uma só consoante? Por que coloca uma consoante para "representar" uma palavra? Por que não usou o número 1 que também encontramos comumente em escritas infantis para indicar artigo indefinido masculino ou numeral? Seria uma "falha no valor sonoro convencional", como diriam alguns estudos sobre a psicogênese da ortografia? Poderia ser uma "hipercorreção" ligada à "generalização de uma regra”, já que o aluno "sabe" que a forma $\mathrm{L}$, em certas posições, tem som $/ \mathrm{u} /$ ? $\mathrm{Ou}$, ao contrário, tal erro poderia ser uma "falta de conhecimento" ou de "infor- mação": o aluno, nesse momento de seu aprendizado das propriedades da língua escrita e do sistema ortográfico, não analisou suficientemente bem esse sistema a ponto de compreender o que é uma "palavra" e que na posição de "artigo" ou "numeral" não há a possibilidade de se grafar somente uma "consoante”? Que tipo de interferência há na relação fonema-grafema que produz uma ruptura com aquilo que tem o "ar de evidência", a saber, usar a letra "U" para representar o som $/ \mathrm{u} /$ ? Como explicar essa falha por meio da noção de "consciência fonológica", pois, pelo que se observa ao longo desse manuscrito, o aluno parece conhecer bem as possibilidades de relação grafo-fônicas entre as formas L e U?

Qualquer resposta que coloca o "conhecimento" ou a "consciência" do aluno como ponto de origem de seu erro parece-nos insuficiente. Suspeitar da certeza dessa relação "consciente" entre o aluno e a língua escrita faz com que interroguemos a natureza e o estatuto dessa relação e nos obriga a sermos mais cautelosos em nossas certezas "científicas". A "ladainha das certezas", como diz Calligaris na epígrafe deste artigo, impede que possamos de vez em quando "suspender a familiaridade das palavras ou expressões irremediavelmente presentes no cotidiano e deixar-se tomar pela perplexidade que essa suspensão instaura”, como diz Lemos (1986, p. 5).

Essa posição tão inesperada da forma $\mathrm{L}$ no lugar de artigo ou numeral coloca em questão até mesmo o estatuto de vogal e consoante ou, ainda, de palavra. Apesar de esses "erros" não apresentarem uma freqüência sistemática nem estarem indexados nos estudos sobre aquisição do sistema ortográfico, as emergências dessa forma nessas posições impõem uma reflexão sobre o funcionamento da língua e sua relação com o sujeito e, mais especificamente, sobre o que pode interferir nesses erros ortográficos.

Em primeiro lugar, vale destacar que há uma forte identidade entre as formas $\mathrm{L}$ e $\mathrm{U}$ quando com valor fônico /u/, rompendo com os limites estabelecidos pela noção de "palavra" e confundido seu estatuto na medida em que essa 
forma se intercambia com as posições de numeral, artigo definido masculino e artigo indefinido masculino, a ponto de se escrever:

"I U PAI DELA SI CAZADO COM ELA DAQUI A L MES" (manuscrito 2)

"I A MININA SI CAIO AL CHA(0)" (manuscrito 3) "I U VELHI SI TRA(NS)FORMOL NI L PRISIPE" (manuscrito 4)

"UMA BRUXA TRAN(S)FORMOL NI L PRISIPE

LI COMTOL QUI UMA BRUXA LI FESTISOL COM A VARIA DI CORDAO" (manuscrito 5) "UMA MENINA MEIGA LI TIRA 0 L FESTISON" (manuscrito 6)

Se a imprevisibilidade da emergência dessa forma nessas posições traz um certo estranhamento para o pesquisador que a "escuta” e investe em sua análise, mantendo o compromisso ético de que isso diz da relação do sujeito com a língua em alguns momentos, é o próprio aluno que se depara com a diferença dessa semeIhança. Sua hesitação surge no justo momento em que duas formas $\mathrm{L}$ aparecem lado a lado.

\section{Manuscrito 7}

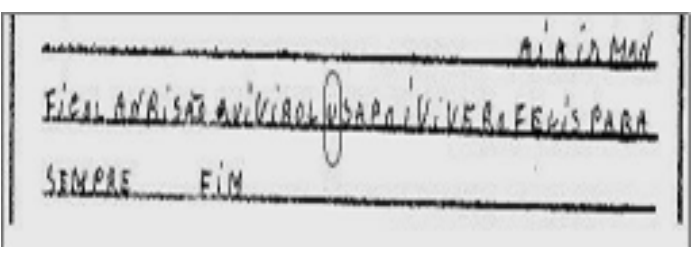

Transcrição do Manuscrito 7 I A IRMAN FICOL TANTA AMBE SÃO QUE VIROL U[L]M SAPO EILES VIVEROS FELIS PARA SEMPRE FIM - (linha 22 e 23)

Como pode ser observado, há aí uma rasura ainda que pouco perceptível. Sob a forma U em "VIROL U SAPO" há a forma L como algo que escapa de um gesto fortuito e nada intencional, mas que vem ocupando a mesma posição anteriormente identificada. A "escuta" que o aluno aqui indicia é efeito não só do estabelecimento de semelhanças entre elas, mas antes da diferença que se deixa a ver no elo entre elas.

São esses equívocos, manifestados ao longo do manuscrito em tela e representados pela forma $\mathrm{L}$ em posições pouco previsíveis, que podem nos ajudar a entender o modo de funcionamento da língua e as relações subjetivas aí instauradas. Subjetividade excluída de todo procedimento metodológico proposto pela Ciência Cognitiva e pelos estudos experimentais. Para esses estudos, tais trocas poderiam ser simplesmente explicadas mediante o conhecimento que o aluno tem das relações entre $\mathrm{L}$ e $\mathrm{U}$ e então o aluno, nesse momento, produziria uma "hipercorreção", isto é, generalizaria uma "informação" que tem, em virtude do que ele "conhece" sobre a grafia de algumas palavras que terminam com a forma $\mathrm{L}$, apesar de o valor fônico ser /u/; e "estendenderia" esse conhecimento para outros contextos lingüísticos. Porém, ainda que a presença da forma $\mathrm{L}$ em posições de artigo masculino indefinido e numeral marque uma possivel relação grafo-fônica entre ela e o som $/ u$ / (fato que poderia ser mais facilmente aceito se a troca fosse apenas entre a forma $\mathrm{L}$ e o som /u/ e não /um/ quando com estatuto de palavra), reduzir essa explicação ao que o aluno conhece ou ainda não conhece sobre as propriedades da língua escrita, obnubila não só o que se entende por "informação" quanto o estatuto desse "conhecimento", pois a presença dessa forma parece marcar mais algo da ordem de um "não-saber" do que um domínio sobre seu funcionamento.

Para se avançar nessa reflexão, é fundamental considerar o princípio de diferencial constitutivo do funcionamento da língua. 0 valor de uma forma significante gráfica e/ou fônica se dá por meio das relações que mantêm com outras formas e suas posições na cadeia sintagmática. É isso que nos permite dizer que as formas $\mathrm{L}, \mathrm{U}, \mathrm{O}$ ou quaisquer outras não têm seu valor em si mesmas nem em uma correspondência direta entre o oral e o gráfico, mas nas relações com o que se tem antes e o que 
há depois e com as posições que as formas podem assumir. Para se entender essas relações, não se pode considerar o valor fônico que elas têm isoladamente como, por exemplo, uma letra do alfabeto e o valor adquirido quando estão no meio de uma palavra.

Além disso, do ponto teórico aqui defendido, no funcionamento da língua, está presente constitutivamente o sujeito e os efeitos dessa relação sobre as próprias possibilidades do sistema e o cruzamento de seus distintos níveis (fônico, sintático, morfológico, ortográfico, gráfico). Logo, essa questão de sujeito e de língua, nessa perspectiva, abandona simultaneamente uma noção de língua como um sistema fechado ao qual o sujeito tenha algum tipo de acesso direto e uma noção de sujeito que se coloque "fora da língua”, isto é, seja capaz de analisar e refletir sobre suas propriedades e categorias sem que elas fossem parte de sua própria possibilidade de "ser sujeito".

\section{Conclusão}

Para entendermos isso um pouco melhor, observemos um ponto bastante importante. A despeito da vinculação entre significado e significante ser arbitrária, como já dizia Saussure (1995), uma vez estabelecidas suas possíveis vinculações, elas formam uma unidade que produz a ilusão de preexistir antes da relação entre elas ${ }^{12}$. Ainda nessa direção, os valores que ganham essas "unidades" (entendese aqui "fonema", "letra", "sílaba" "palavra", "vogal”, "consoante”, "maiúscula”...) dependem da posição em que emergem e do corte na cadeia sintagmática que o sujeito faz. Esses valores guardam uma certa fixidez que camufla seu caráter diferencial e radicalmente arbitrário, apagando diferenças e produzindo para o sujeito a ilusão de sua unidade, de sua semelhança, qual seja fônica, gráfica, ortográfica, parte de uma sílaba, lexema verbal, artigo masculino definido/indefinido, numeral, preposição, número cardinal... Essa é a face imaginária que falamos acima que faz da forma significante uma unidade, isto é, aquilo que nos permite dizer que a forma L é a $12^{\text {a }}$ letra do alfabeto português, o movimento do cavalo no jogo de xadrez e jamais uma palavra.

A constituição dessa face imaginária, necessária e fundante na produção do sentido e também na produção de identificações, é produto de relações estabelecidas pelo modo de funcionamento lingüístico-discursivo no qual o sujeito está inscrito. Explicando com mais palavras, de acordo com o que esses exemplos deixam a ver, a relação entre as formas B, D e O, U e L destaca-se basicamente pelo fenômeno da homofonia, a mesma forma sonora, mas não a mesma forma gráfica, que produz uma certa fragilidade no sistema ortográfico que tanto pode levar à escrita de palavras cuja ortografia não existe na língua como, por exemplo, "a0/Ufabeto", “aprendel/0" ou “jornaU/0", quanto pode produzir problemas de ordem semântica como, por exemplo, "maU" ou "maL", o que a rigor não seria um erro ortográfico.

De maneira um pouco mais aprofundada, nesse último caso, é legitimo dizer que essas formas fonologicamente semelhantes portam diferenças em relação à forma gráfica e ao pertencimento categorial, como entre "abriU" - $3^{\text {a }}$ pessoa do singular do presente do indicativo do verbo "abrir" - e "abril" - substantivo masculino significando o quarto mês do ano - ou diferenças em relação à forma gráfica e à significação lexical como aquelas indicadas por "oUvido" - substantivo masculino ("órgão de audição e de equilíbrio dos vertebrados") - e por "olvido" substantivo masculino ("ato, processo ou efeito de olvidar[-se], esquecer[-se]; esquecimento, olvidamento, deslembrança"). Ou também por "auto" - cerimônia pública - e "alto" - de grande dimensão vertical; de altura superior à média; elevado - dentre tantas outras.

Esses são alguns exemplos de relação entre as formas B, D e $0, \mathrm{U}$ e $\mathrm{L}$, cuja base explicativa pode ser dada a partir das relações fônicas e estruturais da sílaba, como no caso

12. Sobre esta questão, conferir Milner (2002). 
da forma $\mathrm{L}$ ter somente valor fônico de $/ \mathrm{u} /$ quando precedida de vogal e sucedida de consoante ou da forma vazia (“Æ”). Contudo, como não há uma porta de entrada no funcionamento da língua e como a permanência de umas depende do recalcamento de outras (Felipeto, 2004), essas relações não são únicas, completas ou causais nem, diriamos, da instância de uma ordem consciente e analítica.

Para finalizar, trazemos aqui uma possivel resposta à questão exposta no REL, de que "se a alfabetização for considerada um fenômeno natural, resultante da exposição a textos num ambiente letrado, como explicar que milhões de adultos permaneçam incapazes de ler e escrever de forma adequada?" (p. 13, grifo nosso).

Em primeiro lugar, não é de espantar que uma metodologia que procure a generalidade, quando se trata de educação e, portanto, de sujeito e linguagem, não tenha como olhar para as singularidades locais do complexo e problemático sistema educacional brasileiro. Em segundo, as variáveis são tantas que seu apagamento acaba produzindo a ilusão de que é o método de "imersão em textos" o vilão, a causa da problemática. Professores malformados, que escrevem tão igual quanto aos seus alunos, salários que podem levar a um descompromisso com o ensino, falta de acompanhamento e supervisão do trabalho do professor em sala de aula, falta de estrutura física e material nas escolas etc. não podem ser consideradas variáveis nulas ou, ao menos, que se possam descartar em nome da generalidade ou de um método, seja o "inovador" método grafo-fônico ou qualquer outro.

Compreendemos que o "natural" no que se refere ao processo de Aquisição de linguagem mencionado pelos autores do REL passa a ser, segundo Lemos (1992), "atribuído à própria relação entre a criança e o Outro visto como intérprete - doador de sentido - a seus comportamentos" (p. 151). 0 caráter irreversível da captura pelo simbólico, atestado pelo fato de não conseguirmos mais nos colocar fora de seus efeitos, mostra um movimento que vai da captura à percepção/consciência, ou seja, a consciência seria um efeito que se daria a posteriori, após nossa apreensão pelo simbólico. 0 sujeito, assim, teria direito à existência.

\section{Referências bibliográficas}

ABBAGNANO, N. Dicionário de filosofia. São Paulo, Martins Fontes, 2000.

ADAMS, M. J. Beginning to read: thinking and learning about print. Cambridge, Mass: The MIT Press, 1990.

ADAMS, J. J.; BRUCK, M. Word recognition: The interface of educational policies and scientific research. Reading and Writing: An Interdisciplinary Journal, v. 5, p. 113-119. 1993.

BARTHES, R.; MARTY, E. Oral/escrito. Enciclopédia Einaudi: oral/escrito/argumentação. Lisboa, Maiadouro: Imprensa NacionalCasa da Moeda., v. 11, 1987.

BOSCO, Z. R. No jogo dos significantes: a infância da letra. Campinas: Pontes, 2002.

BARRERA, S. D.; MALUF, M. R. Consciência metalingüística e alfabetização: um estudo com crianças da primeira série do Ensino Fundamental. Psicologia: reflexão e Crítica, v. 16, n. 3, p. 491-502, 2003.

BRASIL. Relatório final do grupo de trabalho Alfabetização Infantil: os novos caminhos. Comissão de Educação e Cultura da Câmara dos Deputados. Apresentado no seminário 0 Poder Legislativo e a Alfabetização Infantil: os novos caminhos. Brasília, 15 de setembro de 2003.

BRADLEY, L.; BRYANT, P. E. Categorizing sounds and learning to read: a causal connection. Nature, v. 30, p. 419-421, 1983.

CALIL, E. D'efeitos d'a(língua): o fenômeno lingüístico 'homortográfico'. In: CALIL, E. (Org.) Trilhas da escrita: autoria, leitura e ensino. São Paulo: Editora Cortez. (no prelo) 
CARVALHO, G. M. M. de. Erro de pessoa: levantamento de questões sobre o equívoco em aquisição da linguagem. 1995. 155p. Tese (Doutorado)- Instituto de Estudos da Linguagem, Universidade Estadual de Campinas. Campinas,1995.

CHEMAMA, R. Dicionário de psicanálise-Larousse. Porto Alegre: Artes Médicas, 1995.

CRISTAL, D. Dicionário de lingüística e fonética. Rio de Janeiro: Jorge Zahar Editor, 1997.

FELIPETO, S. C. S. Rasuras entre o oral e 0 escrito: 0 equívoco na altercação. 2004. Tese (Doutorado)- Programa de PósGraduação em Letras e Lingüística, Universidade Federal de Alagoas. Maceió, 2004.

GADET, F. Saussure, une science de la langue. Paris: PUF, 1987.

GONÇALVES, M. F. Madureira Feijó ortografista do século XVIII: para uma história da ortografia portuguesa. Lisboa: ICALP, 1992.

LACAN, J. Escritos. Rio de Janeiro: Zahar, 1996.

LEITE, N. V. de A. Sobre a singularidade. Caderno de Estudos Lingüísticos, v. 38. Campinas: UNICAMP/IEL, 2000.

LEMOS, C. T. G. Interacionismo e aquisição de linguagem. DELTA: Revista de Documentação de Estudos em Lingüística Teórica e Aplicada, v. 22, p. 231-248, 1986.

. Sobre o ensinar e 0 aprender no processo de aquisição da linguagem. Caderno de Estudos Lingüísticos, Campinas, v. 22, p. 149-152, jan./jun. 1992.

Processos metafóricos e metonímicos: seu estatuto descritivo e explicativo na aquisição de língua materna. (Trabalho apresentado no Treton Lectures and Workshop on Metaphora and Analogy, organizada pelo Instituto per la Richerca Scientifica e Tecnologica italiano em Povo, Trenton, 18 a 21 de junho de 1997). Mimeo.

Em busca de uma alternativa à noção de desenvolvimento na interpretação do processo de aquisição de linguagem: parte ll. Relatório do projeto científico de produtividade em pesquisa. São Paulo, Unicamp, 1999. Mimeo.

LEMOS, M. T. G. de. A língua que me falta: uma análise dos estudos em aquisição de linguagem. Campinas: Mercado de Letras; Fapesp: São Paulo, 2002.

LIER-DE-VITTO, M. F. Sobre a posição do investigador e a do clínico frente a falas sintomáticas. Letras de Hoje, v. 39, n. 3, p. 4759, setembro, 2004.

LOPES, A. A singularidade do erro ortográfico e os efeitos do funcionamento da língua. 2005. Tese (Doutorado) - Programa de pós-graduação em Letras e Lingüística, Universidade Federal de Alagoas, 2005.

MILNER, J.-C. 0 amor da língua. Porto Alegre: Artes Médicas, 1987.

Introduction à une science du langage. Paris: Éditions du Seuil, 1989.

Le périple structural: figures et paradigme. Paris: Éditions du Seuil, 2002.

MORAIS, A. G. de. Ortografia: ensinar e aprender. São Paulo: Ática, 1998.

(Org.) 0 aprendizado da ortografia. Belo Horizonte: Autêntica, 2002.

MOREIRA, N. R.; PONTECORVO, C. Chapeuzinho/cappucetto: as variações gráficas e a norma ortográfica. In: FERREIRO, E. (Org.) Chapeuzinho Vermelho aprende a escrever: estudos psicolingüísticos comparativos em três línguas. São Paulo: Ática, 1996.

MOTA, S. B. V. da. 0 quebra-cabeça: a instância da letra na aquisição da escrita. 1995. Tese (Doutorado) - Pontifícia Universidade Católica, São Paulo, 1995.

NUNES, T. et al. Dificuldades na aprendizagem da leitura: teoria e prática. São Paulo: Cortez, 2000. 
PERRONI, M. C. 0 que é o dado em aquisição da linguagem? In: CASTRO, M. F. P. de (Org.) 0 método e o dado no estudo da linguagem. Campinas, SP: Editora da UNICAMP, 1996.

POTHIER, B. Comment les enfants apprennent l'orthographe: diagnostic et propositions pédagogiques. Paris: Retz, 1996.

RAJAGOPALAN, K. 0 singular: uma pedra no caminho dos teóricos da linguagem. In: LEITE, N. V. de A. (Org.). Caderno de Estudos Lingüísticos, v. 38, Campinas, UNICAMP/IEL, jan./jun. 2000.

REGO, L. L. B.; BUARQUE, L. L. Consciência sintática, consciência fonológica e aquisição de regras ortográficas. Psicologia: reflexão e crítica, v. 10, n. 2. Porto Alegre, 1997.

Algumas fontes de dificuldade na aprendizagem de regras ortográficas. In: MORAIS, A. G. (Org.) 0 aprendizado da ortografia, Belo Horizonte: Autêntica, 2002.

REGO, L. L. B.; BRYANT, P. E. The connection between phonological, syntactic and semantic skills and children's reading and spelling. European Journal of Psychology of Education, v. VIII, n. 3, p. 235-246, 1993.

SAUSSURE, F. de. Curso de lingüística geral. São Paulo: Cultrix, 1995.

SMITH. F. Understanding reading. New York: Holt: Rinehart \& Winston, 1971.

Psycholinguistics and reading. New York: Holt: Rinehart \& Winston, 1973.

TAFLA, T. R. Uma visão lingüística do desempenho ortográfico em crianças normais e em crianças portadoras de deficiência mental. 1994. Dissertação (Mestrado) - Faculdade de Filosofia, Letras e Ciências Humanas, Universidade de São Paulo. São Paulo, 1994.

Eduardo Calil é pós-doutor em Aquisição de Linguagem (ITEM/CNRS). Pesquisador associado ao CNPq. Coordenador do projeto integrado de pesquisa "Manuscritos Escolares e Processos de Escrituras" (MEPE). Coordenador geral do grupo de pesquisa "Escritura, Texto \& Criação" (ET\&C). Professor da Universidade Federal de Alagoas.

Adna de Almeida Lopes é doutora em Lingüística. Professora do Curso de Graduação em Letras do Centro de Ciências Humanas Letras e Artes e pesquisadora do projeto integrado "Práticas de textualização na escola" do Centro de Educação, na Universidade Federal de Alagoas/UFAL.

Cristina Felipeto é doutora em Lingüística. Professora da Universidade de Ciências da Saúde de Alagoas - UNCISAL - e coordenadora do projeto de pesquisa " 0 sujeito e a escuta na clínica de linguagem a partir da análise do diálogo pacientefonoaudiólogo". 